ready become a branch of surgery he cannot despise, but to which he must gire more attention in future. Some difference of opinion exists between Mr. W. Adams and Mr. Syme as to the position of certain tendons, such as the posterior tibial, in varus; but the surgeon will seldom be at a loss make out this or the three tendons necessary to remember in these cases, all or some of which are usually the seat of operation.

A very great variety of club-foot cases are operated on here during the year. In a case last week, Mr. Lonsdale pointed out the posterior tibial tendon riding over the bone, instead of being situated behind in its normal position, and the anterior tibial also quite displaced; while, in other cases of congenital and uncongenital talipes, the utmost variety exists. There is a certain tactus eruditus necessary, in fact, in discovering the precise amount of tenotomy necessary in each case, which is not anywhere so observable as in the practice of the Orthopadic Hospital. If practice make tenotomy perfect, as it is supposed to do in other things, the young practitioner will see very gratifying results at this institution. A word of caution may be necessary; viz., that the discussions on tenotomy must be all left out of view, if the visitor or surgeon wish to see for himself, and study nature. Cases of talipes varus are the most common; and, next to these, cases of talipes equinus; the former being remedied by the operation of dividing the three tendons and fascia; and the latter (a condition where the patient walks, as a horse, on the front edge of the foot or toes) are more generally cured by section of the tendo Achillis alone, a simple figure of 8 bandage being afterwards applied, and a Scarpa's shoe used. In the latter cases, as may be easily conjectured, the astragalus sometimes becomes displaced, and the case is more difficult of treatment. Talipes calcaneus, in which the patient walks on his heel (the third variety of deformity), we have also recently seen; but it is more rare than the other two; while talipes valgus, or eversion of the foot, is the rarest of all. In valgus, the extensor communis and peroneus are both divided, with the best results. It is rery desirable, perhaps, that these various classes of surgical cases were more studied by pupils, as many of the cases in actual practice arise only from partial paralysis in children, the result of dentition. Here, of course, apparatus of any kind must only do harm, but scicntific medical treatment much good.

K.

\section{Origimal Communications.}

INGOINAL ANEURISM: IIGATURE OF THE EXTERNAL ILIAC ARTERY CLOSE TO ITS ORIGIN FROM THE COMMON ILIAC : SEPARATION OF THE LIGATURE ON THE FORTY-SIXTH DAY : RECOVERY.

By Wilimar Phinpot Brookes, M.D., F.R.C.S.E., Surgeon to the General Hospital and Dispensary, Cheltenham.

Josepr Sandiuaxds, aged 57 years, cabinet-maker, rcsiding at 34, New Street, Cheltenham, of a spare cachectic habit, looking some years older than he is, of a gouty tendency, and with arcus senilis very distinctly marked, is the subject of the present case. The heart and other visceral organs were quite healthy. Two years since, while using his brace to drill a bedstead, the head of which pressed upon the right groin in working it, on a sudden he felt great pain in the groin, and, for a month afterwards, he could seldom walk. A swelling appeared in the part this for a time seemed improving, and caused him so little pain that he consulted ro surgeon till, some six months after the accident, he again found much pain, and, upon closely examining the groin, discovered a small swelling, which he could hardly touch, from the acuteness of the sensation. It now pulsated strongly, and gradually in- areased in sire. He therefore became alarmed, and consulted Mr. C. Gregory, a surgeon, who at once discorered the character of the tumour, and desired me to see the patient.

Feb. 1st, 1856. Upon examination of the patient, I found an aneurism in the right inguinal region, of the size of a turkey's egg, pulsating rery forcibly: its coverings were tense, but sound, not discoloured. It had considerably forced Poupart's ligament upward out of its natural position. Pressure on the external iliac artery gare so much acute pain that he could not allow it. The pressure but slightly restrained the pulsation in the ancurism. There was no aneurismal indication in any other part of the body. The general health was good, although he looked soma years older than he was. On a careful consideration of all the points of the case, I felt satisfied that treatment by pressure could not be carried out. I determined to tie the external iliac artery as near its origin to the common iliac as could with safety be accomplished, to insure a sufficient clot. The patient readily gave his consent; and, on the 13 th of February, 1856, in the presence of numerous professional friends, I performed the operation at his residence. Making a semilunar incision of five inches in length, commencing somewhat above the anterior superior spinous process of the ilium, and extending to within an inch of the pubis, its convexity looking downwards, I dissected this flap; then, dividing the aponeurosis of the external oblique muscle, reflecting it upwards, and, passing my finger through the fascia transversalis, coming upon the sac of the peritoneum, I carefully pushed it upwards and in wards as far as possible, and reached the artcry. I was now compelled to use the retractors, to keep the parts clear. The division of a small arterial branch, which bled most profusely, gave some trouble: one end being ligatured, and still continuing to bleed from the other, an assistant kept pressure upon it. I secured the external iliac artery, after carefully separating it from its accompanying vein with $\mathrm{my}$ finger nail, and tied the vessel as high up and as far from the diseased portion of the artery as I possibly could. My ligature was waxed thick silk, which was tied in a double knot. All pulsation in the tumour immediately ceased. Both ends of the silk were brought out, and the wound was united with sutures. During the administration of chloroform, which was kindly given by Mr. Hartley, the resident surgeon of the Cheltenham Hospital, the patient became much excited; he had, however, no knowledge of the operation until placed in bod, and some minutes had elapsed after its completion; and his delight was not small when told that all was over. The limb was envelcped in flannel; a warm brick was kept to his foot; bags filled with baked bran were placed down each side of the thigh and leg; and the extremity was kept bent upon the pelvis.

Evening. Pulse 92, and quiet; tongue moist; foot and leg warm; the feeling in the limb was as acute as ever. He complained of slight flatulence. There was no abdominal tenderness. He begged to be allowed a pipe, having for years been accustomed to smoke several during the day, saying that he should not sleep unless he had one. I consented; and he worked at it most heartily. He also took a cup of gruel. The aneurismal tumour in the groin was not perceptible: no kind of pulsation could be felt on most careful examination.

Feb. 14th. Pulse 72, and good; tongue moist. He slept but little; had no abdominal pain. The foot and leg being warmer than the other, I merely kept the warm brick to the foot, and left off the flannel and bran. He said a slight pulsation had returned in the groin.

Feb. 15th. He slept well all night. Pulse 82, soft; tongue clean. The bowels had not been acted upon since the operation. The wound had united by the first iutention. All other symptoms were favourable. The ancurismal tumour had somewhat returned, and pulsated slightly. No trace of pulsation in the femoral or popliteal could be discovered.

Feb. 17th. The patient was progressing favourably. The foot and leg were kept warm; the sutures were taken 
out of the wound, which was perfectly united. The tumour was larger, and pulsated more. Pressure orer the situation of the femoral, below the tumour, entirely controlled the pulsation in the aneurism. There was some discoloration and cedema over the posterior and upper part of the ilium to-day. Warm fomentations readily dispelled it. The bowels were freely opened. He had been kept on low diet until this day, when some meat was allowed him.

Feb. 19th. He continued to go on well. The tumour still pulsated, and appeared to receive its supply of blood by a retrograde circulation, as pressure on the femoral (which could now be discovered pulsating feebly just below the aneurism, but in no other portion of its course) entirely controlled the pulsation through the tumour. No throb could be felt in the artery above the aneurism, or in the popliteal space. He complained to-day of some pain in the leg and knee; this he attributed to the severe frosty weather which set in the previous night. He stated that the cold tried him much, and we could not keep the temperature of his room high enough for him. He was directed to take twenty drops of tincture of opium; this procured him a good night's rest, and all pain in the left knee disappeared.

Feb. 23rd. Going on well. It was found necessary to reduce his diet, as the meat disagreed; and he now took it every other day. The aneurism still pulsated, but was getting smaller. Upon coughing, he stated he felt a darting, shooting pain, in the situation of the ligature.

Feb. 29th. He was going on very well. The aneurismal tumour pulsated; it was becoming much harder and smaller. He could now, for the first time for some months, lie over upon his left side without pain; this he could not attempt prior to the artery being ligatured, and the slightest pressure on the aneurism gave him intense agony; but, since the operation, that had entirely ceased. He was ordered to have the whole of the leg and thigh bandaged, using slight pressure over the groin.

March 5th. I gently tried the ligature, without any result. The aneurism was harder, much diminished in size, and pulsated less. The bandaging was ordered to be kept up.

March 9th. The pulsation in the aneurism had becn gradually getting weaker. The sac was more consolidated and on March 8th, in a moment, at two o'clock, all pulsation suddenly ceased. The man said it was so sudden that it startled him, and he pulled his watch from under his pillow to observe the time. I fancied the ligature gave slightly. To-day he complained that, during the night, his foot felt numbed; it was wrapped in flannel, and the warm brick applied to it: in fact, the brick had been rarely discontinued since the operation. I also had some baked bran applied to the leg. The bowels were costive, and required castor oil occasionally. The diet was improved; he was directed to take meat twice a day.

March 12th. No pulsation had returned. The tumour was gradually becoming absorbed; the foot and leg were quite comfortable; the appetite good. Bandaging of the limb had been discontinued since the 9 th.

March 13th. His tongue was clean, and he had but little constitutional irritation. He was ordered to take two grains of quinine three times a day, and as much Guinness's stout as he could comfortably drink, with generous dict.

March 15th. Yesterday he found a pain in the knee, which he persisted in stating to be rheumatism. There was also a slight reddish blush around the situation of the aneurism. To-day, upon my visit, I found erysipelas and cedema around the upper part of the thigh and groin, involving the aneurism, which was most painful upon the slightest touch. I requested him to carefully aroid handling the part, or permitting any of the medical gentlemen who took an interest in the case, and visited him, to touch it. The tongue was clean and moist; the pulse calm; the bowels freely opened; he had little or no constitutional irritation. The thigh was dressed with lint, dipped in a warm solution of poppy-head infusion; and the wet lint was corered with oil silk. For the first time since the operation, I allowed him some beer. The erysipelas did not extend around the ligature or cicatrix of the wound.

March 16th. Countenance anxious. The cedema and erysipelas had much subsided; tongue clean; bowels opened; pulse quicker than it was yesterday. IIe slept but little; did not take the beer. IIe was ordered to continue the warm application, and to take two grains of Dover's powder at bedtime. 'The urine was much loaded with lithates.

March 17th. The urine was natural to-day. The erysipelas had left the situation of the groin, and now occupied the middle of the thigh. I applied caustic around and over it in several places, and kept on the warm dressing. He was ordered to take beer.

March 18th. He slept well. The erysipelas did not extend; the caustic appeared to have restrained its course. $\mathrm{Ue}$ looked anxious; pulse quick; tongue moist; appetite bad. He took, to-day and yesterday, half a pint of beer. He was directed to have onc tablespoonful of cod.liver oil and quinine thrice a day.

March 19th. He slept well. The erysipelas was better; the appetite improved; pulse 100 . Lint, dipped in warm water, was applied, and covcred with oil silk.

March 20th. Improving. IIe was taking nearly a quart of beer daily. There was still much odema of the upper part of the thigh; but the crysipelas had nearly subsided.

March 21st. He was going on satisfactorily. He took his food and beer well. Slight fluctuation on the inside of the thigh was discovered to-day; but, on passing a grooved needle, no pus escaped.

March 27th. $\Lambda$ distinct point had formed, which fluctuated freely. He stated that, for the last two days, he had suffered great pain; but he did not call to his assistance any one during my absence from Cheltenham (which had been for three days), although I had ordered him to do so, but waited for my return. The fluctuation was chiefly in the middle and inner part of the thigh. There was also a soft point in the situation of the sac. The pus was confined under the fascia. On making a deep incision at the depending point, a large quantity of pus, mixed with dark grumous coagulated portions of blood, of a most offensive character, escaped. That portion situated in the sac of the oneurism communicated with and was emptied by the lower outlet. It was evident that the sac had suppurated, and that this was the original seat of the erysipelatous inflammation. I bandaged the upper portion of the thigh, using gentle prossure; and wet lint was kept on the depending point for the escape of the matter.

March 28 th. Pulse quiet, but feeble. There were scarcely any constitutional symptoms. About four ounces of pus were discharged, of a more healthy character. I placed an India rubber band between the two ends of the ligature, and strapped it up to the abdomen, my object being to keep steady and gentle extension on the ligature.

March 30th. The discharge from the thigh was much diminished. He continucd his porter and quinine, and was gradually gaining strength. Ile stated that the ligature was pulled much by the band, and caused some pain during the night. On touching it, I found it yield; and, on replacing the band, the ligature came away; this being the forty-sixth day from the operation, not including the day of its performance. That portion of the ligature which surrounded the artery readily allowed the passage of a good sized goose-quill through it.

March 31 st. The discharge from the thigh was rery trifling. Upon pressure around the spot from which the ligature escaped, a discharge of pus took place: pressure up the thigh also caused the same discharge from this point. He had no abdominal tenderness, and bore pressure orer the abdomen with ease.

April 12th. IIe had gained strength, and walked about. All discharge, both from the thigh and abdomen, had ceased.

April 24th. He was quite well. The sac of the aneurism could barely be discovered. Upon very accurate examination, a small hardened spot was felt in its situation. The 
patient now walked some distance daily, and anid he felt trong. Ho has gained much flesh; the foot and leg are of their.natural warmth. He walks with the limb as strongly as ever; the circulation in it is powerful, and perfectly reeateblished.

\section{ILLUSTRATIONS OF THE PATHOLOGY OF CANCER.}

By J. Zachariuh Lauresce, Esq., F.R.C.S. Part I (concluded).

GRABRAL CHARACTERS AND CLASSIFICATION OF CANCEROUS TUMOURS.

Mr. Paget had, in 1853, reason to " suspect cases (of myeloid tumours) may be found in which ... a malignant course is run."* Since the time he wrote this, this suspicion has become a certainty - the occasional malignity of fibro-plastic tumours must now take its rank amongst the best established surgical doctrines. M. Lebert has collected six cases of the kind, the main features of which are given in the following tabular exposition.

M. Léopold Ollicr narratcs a case of Fibro-plastic tumour of the back, accompanied by secondary tumours in the inguinal region, both lungs, and the liver. The tumour in the back had been removed by the écrasement linéaire of M. Chassaignac. M. Delore " found in it only fibro-plastic elements". In the lungs werc "little masses of a yellowish white material, pulpy and very soft". In the liver were tumours with "the same outward characters". "In the right inguinal region existed a fluctuating tumour, full of sanguineous serosity and fibrinous deposits". The above description is much more in accordance with that of a case of encephaloid than of fibro-plastic cancer. The figures M. Ollier gives of the microscopic elements, agree more with some of the forms of caudate cancer-cells I have seen, than with those of typical fibro-plantic corpuseles: they are, at any rate, open to doubt, 2 is indeed tho whole case.t

Dr. Follin, in a recent letter, writes me, that " since that time (vir., the publication of Lebert's cases), wo have had on more than one occasion the opportunity of observing analogous facts in the Paris hospitals."

The following case, from my essay On the Diagnosis of Surgical Cancer, is intermediate in its characters between fibrous and fibro-plastic cancer.

CAsE. An old man, aged 65 years, of a muscular frame and florid complexion, had a very large tumour at the lower end of his left thigh. It was about the size of a walnut when he first observed it some two years before; but had since progressively increased to its present size. There were no inguinal enlargements. He had suffered occasional "scalding" pains in the part. There was no cancerous predisposition to be traced; but some of his brothers and a sister had died of phthisis. This man died from the effects of chloroform administered for the purpose of amputation of the thigh. At the post mortem, a tumour was noticed on the left arm, which, somehow, had escaped notice during life: one in the substance of the liver, and some deposits in the lungs. A section of the tumour of the thigh presented all the naked eye characters of a fibrous tumour (propr. sic dict.), just as is obscrved in ordinary fibrous tumours of the uterus. At one spot, however, a considerable hæmorrhagic effusion had occurred into the substance of the growth. The microscopic characters of the tumours were equally distinctive. Large quantities of fibres, for the most part parallelly arranged, constituted the main element. Some few fibro-plastic cells, here and there an elongated nucleus (brought out by acetic acid, which effaced the fibres), and a number of fatty molecules, were the secondary elements. Not a single cancer cell could be seen. The tumour from the arm was about the size of an olive, and its section was characterised

M. Lebert's Cases of Malignant Fibro-Piastrc Tumotrs.

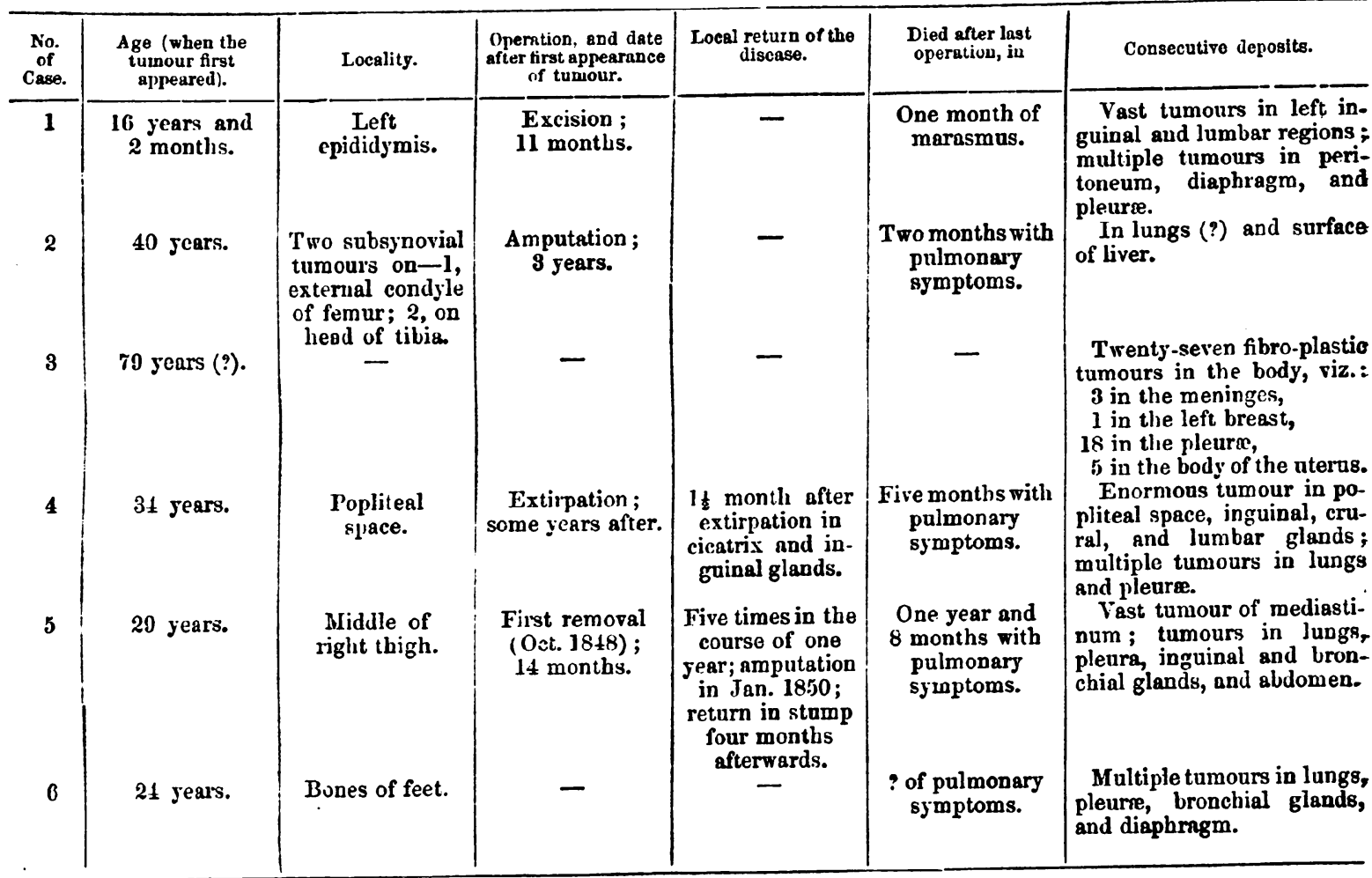

- Op. cit., vol. ii, p. 225.

+ Recherches Anatomo-Pathilogiques sur la

Lopold Ollier. Mont pats: 1856. (p. 194.) 